\title{
Soft Tissue Sarcoma pN1 TNM Finding v7
}

National Cancer Institute

\section{Source}

National Cancer Institute. Soft Tissue Sarcoma pN1 TNM Finding v7. NCI Thesaurus. Code C88463.

Soft tissue sarcoma with regional lymph node metastasis. Note: Presence of positive nodes (N1) in M0 tumors is considered Stage III. (from AJCC 7th Ed.) 